Correspondence

Hanne C. Winther-Larsen

hannewi@imbv.uio.no

Received 18 February 2009

Revised 27 April 2009

Accepted 2 May 2009

\section{Functional analyses of pilin-like proteins from Francisella tularensis: complementation of type IV pilus phenotypes in Neisseria gonorrhoeae}

\author{
Emelie Salomonsson, ${ }^{1,2}$ Åke Forsberg, ${ }^{1,2}$ Norbert Roos, ${ }^{3}$ Claudia Holz, ${ }^{4}$ \\ Berenike Maier, ${ }^{4}$ Michael Koomey ${ }^{3,5}$ and Hanne C. Winther-Larsen ${ }^{3,5} \dagger$
}

\author{
${ }^{1}$ CBRN Defence and Security, FOI Swedish Defence Research Agency, Cementvägen 20, 90182 \\ Umeå, Sweden \\ ${ }^{2}$ Umeå Centre for Microbial Research (UCMR) and Laboratory for Molecular Infection Medicine, \\ Sweden (MIMS), Department of Molecular Biology, Umeå University, 90187 Umeå, Sweden \\ ${ }^{3}$ Department of Molecular Biosciences, University of Oslo, 0316 Oslo, Norway \\ ${ }^{4}$ Westfälische Wilhelms-Universität Münster, Institut für Allgemeine Zoologie und Genetik, 48149 \\ Münster, Germany \\ ${ }^{5}$ Centre for Molecular Biology and Neuroscience, University of Oslo, 0316 Oslo, Norway
}

\begin{abstract}
Accumulating evidence from a number of studies strongly suggests that proteins orthologous to those involved in type IV pili (Tfp) assembly and function are required for Francisella pathogenicity. However, the molecular mechanisms by which the components exert their influence on virulence remain poorly understood. Owing to the conservation and promiscuity of Tfp biogenesis machineries, expression of Tfp pilins in heterologous species has been used successfully to analyse organelle structure-function relationships. In this study we expressed a number of Francisella pilin genes in the Tfp-expressing pathogen Neisseria gonorrhoeae lacking its endogenous pilin subunit. Two gene products, the orthologous PilA proteins from Francisella tularensis subspecies tularensis and novicida, were capable of restoring the expression of Tfp-like appendages that were shown to be dependent upon the neisserial Tfp biogenesis machinery for surface localization. Expression of Francisella PilA pilins also partially restored competence for natural transformation in N. gonorrhoeae. This phenotype was not complemented by expression of the PulG and XcpT proteins, which are equivalent components of the related type II protein secretion system. Taken together, these findings provide compelling, although indirect, evidence of the potential for Francisella PilA proteins to express functional Tfp.
\end{abstract}

\section{INTRODUCTION}

The Gram-negative facultative intracellular bacterium Francisella tularensis causes the zoonotic disease tularaemia (Mörner, 1992; Tärnvik, 1989). There are at least four subspecies of $F$. tularensis, each with a unique geographical distribution (Petersen \& Schriefer, 2005). F. tularensis subsp. holarctica (type B) can been found in most of Europe, Asia and North America, while F. tularensis subsp.

tPresent address: Department of Food Safety and Infection Biology, Norwegian School of Veterinary Science, Post Box 8146, 0033 Oslo, Norway.

Abbreviations: DATDH, 2,4-diacetamido-2,4,6-trideoxyhexose; IFM, immunofluorescence microscopy; LVS, live vaccine strain; SOEing PCR, splicing by overlapping extension PCR; T2SS, type II secretion system; TEM, transmission electron microscopy; Tfp, type IV pili.

A supplementary table of primers and four supplementary figures are available with the online version of this paper. tularensis (type A) is found exclusively in North America. F. tularensis subsp. mediasiatica has been identified in Central Asia and, finally, F. tularensis subsp. novicida has been found in numerous locations in North America and in Australia (Petersen \& Schriefer, 2005; Whipp et al., 2003). Human tularaemia infections are usually caused by subsp. tularensis and subsp. holarctica, the former being associated with more severe disease than the latter (Tärnvik \& Berglund, 2003). The significantly less pathogenic subsp. novicida has only been reported to cause infection in immunocompromised individuals on rare occasions (Hollis et al., 1989; Tärnvik, 1989). Due to its high infectivity and capacity to cause severe illness and death, $F$. tularensis is considered a Category A agent of bioterrorism (Dennis et al., 2001; Khan et al., 2000). Compared to other Category A bacterial pathogens, relatively little is known about the virulence factors of $F$. tularensis. However, recent comparative genomic efforts (Svensson et al., 2005) and the 
development of genetic tools (Golovliov et al., 2003) have paved the way for progress in this research field.

The genome sequence of the virulent $F$. tularensis subsp. tularensis strain SCHU S4 contains several gene clusters with potential roles in virulence (Larsson et al., 2005). Amongst these are those encoding proteins related to those required for assembly and secretion of type IV pili (Tfp) (Larsson et al., 2005). Tfp are complex filamentous appendages defined by their shared structural, biochemical, antigenic and morphological features which are expressed by many human pathogens, including Neisseria species, Pseudomonas aeruginosa and Vibrio cholerae (Fullner \& Mekalanos, 1999; Mattick et al., 1996; Tønjum \& Koomey, 1997). Tfp play central roles in the expression of many phenotypes, including multicellular behaviours, natural genetic transformation, biofilm formation, cell signalling, motility and host cell adherence (Källström et al., 1998; Mattick, 2002; O’Toole \& Kolter, 1998). Tfp biogenesis and the elaboration of associated phenotypes require the concerted actions of many proteins that are structurally conserved across species and genus boundaries (Strom \& Lory, 1993). The pilus fibre is mainly composed of the major pilin subunit (called PilA in P. aeruginosa), which is expressed as a prepilin that upon cleavage by the prepilin peptidase PilD allows for proper pilus assembly and function (Strom et al., 1993). Translocation of the pilus to the cell surface is then enabled by the secretin PilQ (Wolfgang et al., 2000). In many instances, multiple proteins sharing structural similarities with the major pilin subunit, so-called minor pilins, are required for proper Tfp function and/or assembly (Alm et al., 1996a, b; Alm \& Mattick, 1996; Helaine et al., 2007; Winther-Larsen et al., 2001, 2005; Wolfgang et al., 1998b). However, their role in Tfp biogenesis and function is still not completely understood. Furthermore, Tfp are dynamic structures that undergo retraction events mediated by members of the PilT retraction ATPase family (Nudleman \& Kaiser, 2004; Skerker \& Berg, 2001; Whitchurch et al., 1991). Rounds of Tfp extension and retraction mediate so called twitching motility on solid and semisolid surfaces (Mattick, 2002), and susceptibility to pilus-specific phages (Bradley \& Pitt, 1974; Waldor \& Mekalanos, 1996).

Many components part of the type II protein secretion system (T2SS) share remarkable similarities with those involved in Tfp expression (Peabody et al., 2003) and, if overexpressed, T2SS pilin-like molecules can polymerize into Tfp-like structures (Durand et al., 2003; Vignon et al., 2003). Despite these similarities, functional interactions between these two systems have only been reported in one instance (Lu et al., 1997). Nonetheless, Tfp systems in $V$. cholerae and Dichelobacter nodosus have been implicated in the translocation of folded proteins from the periplasm to the extracellular milieu (Han et al., 2008; Kirn et al., 2003).

A number of findings suggest that Francisella Tfpassociated genes are involved in pathogenesis. A spontaneous mutant of $F$. tularensis subsp. holarctica with a deletion within a pilin-like gene locus showed reduced virulence in mice, and a similar rearrangement at this particular locus is present in the subsp. holarctica live vaccine strain (LVS) (Forslund et al., 2006). Interestingly, secretion of multiple proteins in F. tularensis subsp. novicida was abolished by mutations in genes predicted to encode Tfp and ancillary factors (Hager et al., 2006), suggesting that $\mathrm{Tfp}$ in this subspecies might also be associated with a T2SS as in D. nodosus and $V$. cholerae (Han et al., 2008; Kirn et al., 2003). Surprisingly, these mutants revealed increased virulence in an animal model (Hager et al., 2006). These perplexing results were reconciled by the observation that $\mathrm{PepO}$, one of the secreted substrates, is a zinc protease that promotes increased vasoconstriction and potentially inhibits tissue spread and dissemination. Interestingly, PepO appears to be absent from the human-virulent Francisella lineages.

Central questions yet to be resolved for Francisella species are what components encompass the pilus machinery and which protein constitutes the major structural subunit. For the LVS, one report concluded that it expresses pilus-like appendages, and many of the genes whose products are predicted to be involved in Tfp biogenesis were shown to be transcribed (Gil et al., 2004). More recently, null mutations in genes encoding a putative Tfp assembly ATPase (PilB, P. aeruginosa nomenclature) and a homologue for PilT were shown to prevent the formation of Tfplike organelles in the LVS (Chakraborty et al., 2008). Importantly, however, studies using the LVS are complicated by the fact that it carries mutations in genes encoding strong candidates of Tfp pilin subunits (based on structural similarities and synteny) (Forslund et al., 2006). Tfp-like appendages have also been observed in $F$. tularensis subsp. novicida, and their expression was shown to depend on the putative assembly and retraction ATPase genes (Zogaj et al., 2008). Intriguingly, mutants lacking homologues of components (PilC and PilQ, P. aeruginosa nomenclature) critical to surface expression of Tfp in other pathogens such as $N$. gonorrhoeae and $P$. aeruginosa were unaltered in organelle expression, but defective in protein secretion and virulence. Conversely, a mutant defective in expression of the pilin-like protein termed PilE4 retained protein secretion and virulence, but lacked Tfp-like organelles (Zogaj et al., 2008). The authors concluded that Tfp expression and protein secretion can be dissociated in subsp. novicida and that PilE4 is probably the major subunit of Tfp. Still, conclusive evidence as to which protein constitutes the major structural subunit has yet to be presented.

In order to address some of these issues, we employed a strategy in which pilin genes from $F$. tularensis were expressed in $N$. gonorrhoeae. Based on the extensive similarity of pilins from different species and the highly conserved nature of the assembly machineries, transspecies complementation has been achieved (Elleman et al., 1986; Hoyne et al., 1992; Sauvonnet et al., 2000; Winther-Larsen et al., 2007). Our results strongly suggest 
that one particular class of pilin protein from subsp. tularensis and its counterpart from subsp. novicida is capable of forming Tfp-like appendages and complementing the Tfp-dependent phenotype of natural genetic transformation in a N. gonorrhoeae pilin subunit mutant.

\section{METHODS}

Bacterial strains, plasmids and growth conditions. The $F$. tularensis, Escherichia coli and N. gonorrhoeae strains used in this study are listed in Table 1. F. tularensis strains were grown on modified Thayer-Martin agar plates (Sandström et al., 1984) and N. gonorrhoeae strains in GC medium or on GC agar (Freitag et al., 1995) plates, both at $37{ }^{\circ} \mathrm{C}$ in a $5 \% \mathrm{CO}_{2}$ atmosphere. E. coli strains were grown on blood agar base (BAB; Merck) plates or in Luria-Bertani broth (LB) at $37{ }^{\circ} \mathrm{C}$. Where appropriate, antibiotics were used at the following concentrations; kanamycin $50 \mu \mathrm{g} \mathrm{ml} \mathrm{m}^{-1}$, chloramphenicol $10 \mu \mathrm{g} \mathrm{ml}^{-1}$ and erythromycin $8 \mu \mathrm{g} \mathrm{ml}^{-1}$. Preparation of plasmid DNA, restriction enzyme digests, ligations and transformations into $E$. coli were performed essentially as described by Sambrook et al. (1989).

Construction of translational fusions. The gonococcal pilE gene (also denoted pilE $E_{G C}$ ) was fused in-frame to the Francisella pilin genes (denoted by subscript Ft for F. tularensis subsp. tularensis and Fn for F. tularensis subsp. novicida) pilA $A_{F t}$ pilE $E_{F t}$ pill $F_{F t}$ FTT0861 $1_{\mathrm{Ft}}$, FTT0230 $\mathrm{Ft}$, FTT1314 $\mathrm{Ft}$ and pilA $F$ at the glycine-phenylalanine junction by overlap extension (SOEing) PCR using primers pilE $\mathrm{GC}_{\mathrm{GC}} \mathrm{F}, \quad$ pilE $\mathrm{GC}_{\mathrm{GC}} \mathrm{R} 1-7, \quad$ pilA $\mathrm{Ft} / \mathrm{pilE}_{\mathrm{Ft}} / \mathrm{pilV}_{\mathrm{Ft}} / \mathrm{FTT} 0861_{\mathrm{Ft}} / \mathrm{FTT} 0230_{\mathrm{Ft}} /$

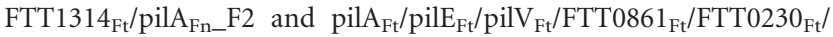

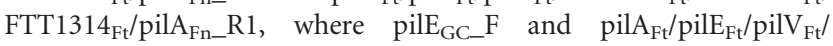

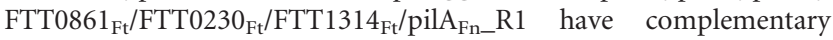
sequences (see Supplementary Table S1, available with the online version of this paper). For $N$. gonorrhoeae, pilE $E_{G C}$ plasmid pPilE2 was used as template and for Francisella, strain FSC237 (subsp. tularensis, SCHU S4) or FSC040 (subsp. novicida, U112). The fusion proteins carry the first seven residues of gonococcal PilE $_{\mathrm{GC}}$ while the remaining protein is Francisella derived. The amplified fragments were digested with Bsu36I and StuI and subcloned into p2/16/1, generating plasmids pEMS25-31. The plasmids were then introduced into gonococcal strains MW24, KS101, GP111 and KS79 by transformation and selection on GC agar plates containing erythromycin as previously described (Freitag et al., 1995). Direct sequencing of PCR products derived from transformants was performed using the primers p2/16/1_5' and p2/16/1_3' to ensure correct sequences (Eurofins MVG Operon).

Construction of T2SS pseudopilin transcriptional and translational fusions. The gonococcal pil $E_{G C}$ gene was fused in-frame to the Klebsiella oxytoca pulG gene and the P. aeruginosa PAK $x c p T$ gene at the translational start site or at the pilin peptidase cleavage site by SOEing PCR. The upstream pilE $E_{G C}$ region was amplified from plasmid pPilE2 using primer 266 (5'-pilE_Sac/Bam) together with HC2 (pilE $E_{G F} p u l G$ ), HC7 (pilE ATG $_{p} p u l G$ ), HC12 (pilE $E_{G F} x c p T$ ) and HC21 ( $p i l E_{A T G} x c p T$ ) (Table S1). The downstream region was amplified from plasmid pCHAP231 using primers HC4 (pilE $E_{G F} p u l G$ ) and HC6 ( pilE $_{A T G}$ pulG) together with primer HC9. Primers HC2 and HC7 had overlapping sequences with primers $\mathrm{HC} 4$ and HC5, respectively. The two PCR products were joined together using the flanking primers 266 and HC10. For $x c p T$, the downstream region was amplified from plasmid pMTWT using primers $\mathrm{HC} 13$ (pilE $\mathrm{E}_{\mathrm{F}} x c p T$ ) and $\mathrm{HC} 19$ $\left(p i l E_{A T G} x c p T\right)$ together with HC24. Primers HC12 and HC21 had overlapping sequences with $\mathrm{HC} 13$ and $\mathrm{HC} 19$, respectively. The two PCR products were joined together using the flanking primers 266 and HC23. The amplified products were cloned into pCRII-TOPO (Invitrogen) giving rise to plasmids pHW10-13. Plasmids pHW10-13 were digested with SacI, and the DNA fragments containing the pilE: :pulG or pilE::xcpT fusions were cloned into plasmid p2/16/1 digested with the same enzyme. The resulting plasmids pHW14-17 were introduced into gonococcal strains by transformation and selection on GC agar plates containing erythromycin. Plasmids were sequenced at GATC Biotech (Konstanz, Germany) using custom primers. PulG and XcpT expression were verified by immunoblotting using antibodies specific for PulG or XcpT.

Gel electrophoresis and Western blot analysis. Protein samples containing SDS and $\beta$-mercaptoethanol were boiled for $5 \mathrm{~min}$. All samples were separated by SDS-PAGE on $12 \%$ or $15 \%$ gels (Laemmli, 1970). Proteins were transferred to Immobilon-P Transfer Membranes (Millipore) using a Trans-Blot Semi-Dry transfer cell (Bio-Rad). Membranes were blocked in Tris-buffered saline (TBS) with 5\% nonfat dry milk. Immunoblotting was performed with polyclonal rabbit

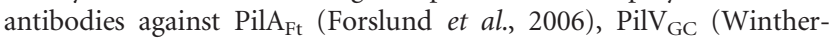
Larsen et al., 2001), PulG, XcpT and Tfp from the gonococcal strain N400 (lot 904) (Winther-Larsen et al., 2007). P. aeruginosa PAK PilAspecific serum was a gift from E. Gotschlich (Rockefeller University). $K$. oxytoca PulG-specific serum was a gift from A. Pugsley (Pasteur Institute, Paris) and $P$. aeruginosa XcpT-specific serum was a gift from A. Filloux (IBSM-CNRS, Marseille Cedex). For the alkaline-phosphatase-conjugated secondary antibody system (Roche), the visualization was accomplished by incubating the filters with $0.1 \%(\mathrm{w} / \mathrm{v}) \mathrm{NBT}$ (nitro blue tetrazolium; Sigma) and $0.05 \%$ (w/v) BCIP (5-bromo-4-chloro-3indolyl phosphate; Sigma).

Immunofluorescence, immunogold and transmission electron microscopy. Immunofluorescence microscopy was performed as described previously (Winther-Larsen et al., 2005). The pili were labelled using gonococcal PilE $_{\mathrm{GC}}$ specific serum (lot 904). Samples for transmission electron microscopy were prepared as published (Winther-Larsen et al., 2007) and viewed in a Hitachi (Tokyo) HU$11 \mathrm{E}-1$ electron microscope. Immunogold labelling was carried out essentially as described previously (Winther-Larsen et al., 2007) using rabbit antiserum specific for $\mathrm{PilE}_{\mathrm{GC}}$ (lot 904). Images shown correspond to fields that were representative of the overall observation. For statistical analysis the percentage of piliation was calculated from at least five sets of experiments in which the number of pili was counted per 600 gonococcal cells.

Tfp purification, transformation and twitching motility assay. Transformation assays were carried out as described previously (Aas et al., 2002). Pili were purified by the ammonium sulphate procedure of Wolfgang et al. (1998a), with modifications (Winther-Larsen et al., 2007). Twitching motility assays were carried out in phenol-red-free DMEM (Gibco), supplemented with $2 \mathrm{mM}$ L-glutamine, $8 \mathrm{mM}$ sodium pyruvate, $5 \mathrm{mM}$ ascorbic acid, $30 \mathrm{mM}$ HEPES and $1 \mathrm{mg}$ BSA ml ${ }^{-1}$ at $37^{\circ} \mathrm{C}$ on glass coverslips (Maier et al., 2004).

\section{RESULTS}

\section{The repertoire of Tfp-related pilin genes in Francisella genomes}

The genome sequence of the $F$. tularensis subsp. tularensis virulent strain SCHU S4 contains multiple ORFs similar to genes encoding components involved in Tfp biogenesis and Tfp structures in other bacterial species (Larsson et al., 2005). These ORFs include six genes whose predicted products have features typical for Tfp prepilins. Genome comparisons between different strains and subspecies of Francisella reveal several differences in the putative Tfp 
Table 1. Strains and plasmids used in this study

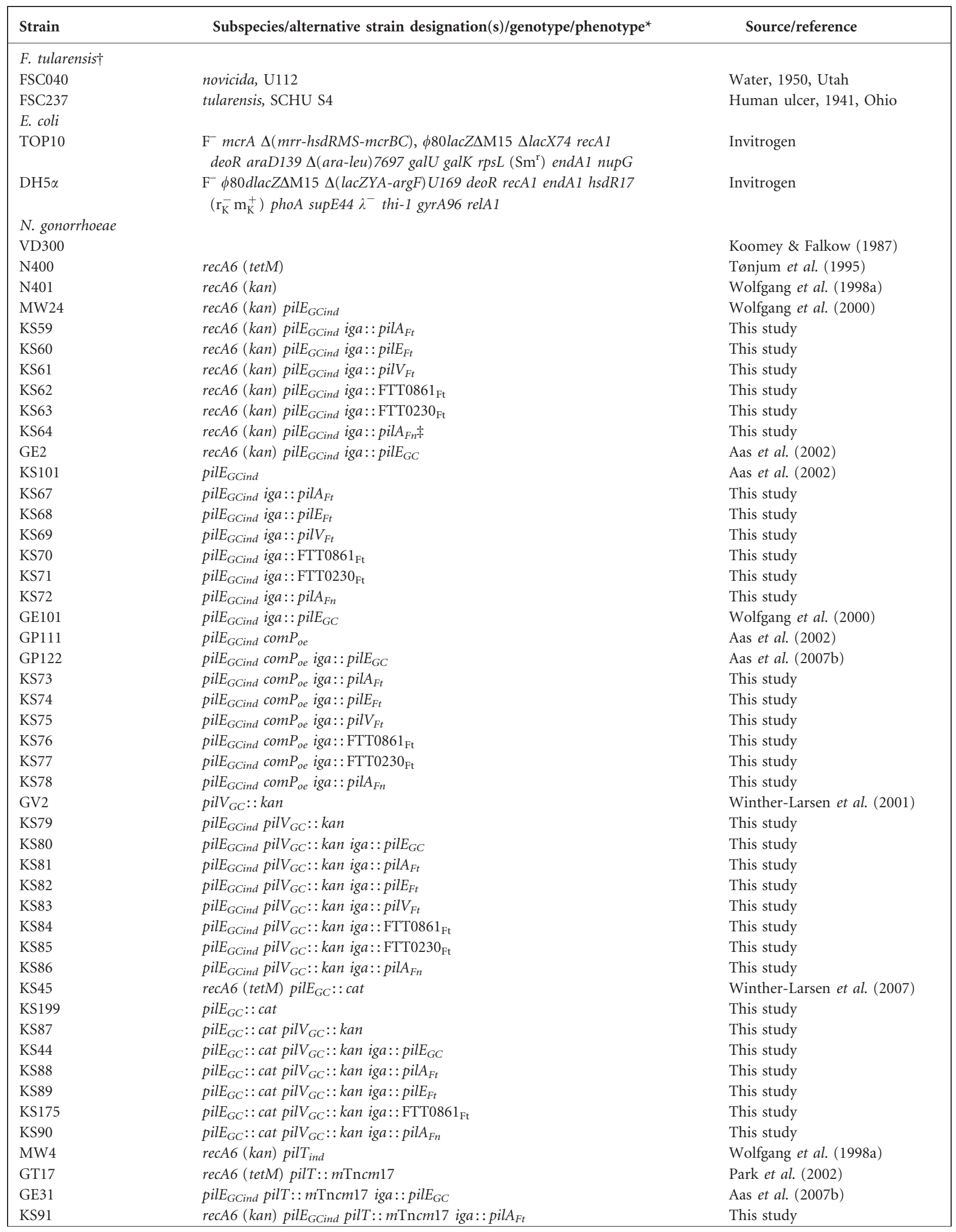


Table 1. cont.

\begin{tabular}{|c|c|c|}
\hline Strain & Subspecies/alternative strain designation(s)/genotype/phenotype ${ }^{\star}$ & Source/reference \\
\hline KS92 & recA6 (kan) pilE $E_{G C i n d}$ pilT:: $m$ Tncm17 iga: : pilE $E_{F t}$ & This study \\
\hline KS93 & recA6 (kan) pilE $G_{G C i n d}$ pilT:: $m$ Tncm17 iga: : pilV $V_{F t}$ & This study \\
\hline KS94 & recA6 (kan) pilE $E_{G C i n d}$ pilT:: $m$ Tncm 17 iga:: FTT0861 $_{\mathrm{Ft}}$ & This study \\
\hline KS95 & recA6 (kan) pilE GCind $_{\text {pilT:: } m \text { Tncm } 17 \text { iga: : FTT0230 }}$ & This study \\
\hline KS96 & 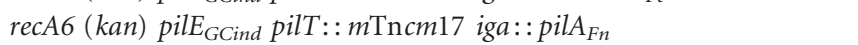 & This study \\
\hline GF101 & recA6 (kan) pilE GCind $_{\text {pilF: : cat iga: : pilE }}$ & Aas et al. (2007b) \\
\hline KS97 & recA6 (kan) pilE ${ }_{G C i n d}$ pilF: : cat iga::pilA $A_{F t}$ & This study \\
\hline KS98 & recA6 (kan) pilE $E_{G C i n d}$ pilF: : cat iga: : pilA $F n$ & This study \\
\hline KS161 & recA6 (tetM) pilM::cat & This study \\
\hline KS162 & recA6 (kan) pilE ${ }_{G C i n d}$ pilM:: cat iga: : pilA ${ }_{F t}$ & This study \\
\hline KS163 & recA6 (kan) pilE $E_{G C i n d}$ pilM:: cat iga::pilA $F n$ & This study \\
\hline KS164 & recA6 (tetM) pilN:: cat & This study \\
\hline KS165 & recA6 (kan) pilE GCind $_{\text {pilN: : cat iga: : pilA }}$ & This study \\
\hline KS166 & recA6 (kan) pilE $E_{G C i n d}$ pilN: : cat iga: : pilA $A_{F n}$ & This study \\
\hline KS167 & pilE $_{G C i n d}$ iga: $: p u l G_{G F}$ & This study \\
\hline KS168 & pilE $_{G C i n d}$ iga: : pulG $G_{A T G}$ & This study \\
\hline KS169 & pilE $_{G C i n d}$ iga: $: x c p T_{G F}$ & This study \\
\hline KS170 & pilE $_{G C i n d}$ iga: : xcp $T_{A T G}$ & This study \\
\hline KS171 & pilE $_{G \text { Cind }}$ pilV $V_{G C}:$ : kan iga:: pul $G_{G F}$ & This study \\
\hline KS172 & pilE $_{G C i n d}$ pilV $V_{G C}:$ : kan iga::pulG $G_{A T G}$ & This study \\
\hline KS173 & pilE $_{G \text { Cind }}$ pil $V_{G C}:$ : kan iga:: $x c p T_{G F}$ & This study \\
\hline KS174 & pilE $_{G \text { Cind }}$ pilV $V_{G C}:$ : kan iga: : xcp $T_{A T G}$ & This study \\
\hline KS141 & pgla:: kan & Aas et al. (2007b) \\
\hline KS180 & recA $\left(\right.$ tetM) pilE $E_{G C}:$ :cat pglA:: kan iga: : pilA ${ }_{F t}$ & This study \\
\hline KS181 & recA $\left(\right.$ tetM) pilE $E_{G C}:$ cat pglA:: kan iga: : pilA ${ }_{F n}$ & This study \\
\hline GGC & pglC:: kan & Hegge et al. (2004) \\
\hline KS182 & recA $\left(\right.$ tetM) pilE $E_{G C}:$ :cat pglC:: kan iga:: pilA $F t$ & This study \\
\hline KS183 & recA (tetM) pilE ${ }_{G C}:$ :cat pglC:: kan iga::pil $A_{F n}$ & This study \\
\hline GGD & pglD:: kan & Hegge et al. (2004) \\
\hline KS184 & recA $\left(\right.$ tetM) pilE $E_{G C}:$ cat pglD:: kan iga: :pilA $A_{F t}$ & This study \\
\hline KS185 & recA $\left(\right.$ tetM) pilE $E_{G C}:$ cat pglD:: kan iga: : pilA $A_{F n}$ & This study \\
\hline KS142 & $p g l E_{O N}$ & Aas et al. (2007b) \\
\hline KS186 & recA $\left(\right.$ tetM) pilE $E_{G C}:$ cat pglE $E_{O N}$ iga: : pilA $A_{F t}$ & This study \\
\hline KS187 & recA $\left(\right.$ tetM) pilE $E_{G C}:$ cat pglE $E_{O N}$ iga: : pilA $F n$ & This study \\
\hline GGF & $p g l F:: k a n$ & Hegge et al. (2004) \\
\hline KS188 & recA $\left(\right.$ tetM) pilE $E_{G C}:$ cat pglF iga: :pilA $A_{F t}$ & This study \\
\hline KS189 & recA (tetM) pile ${ }_{G C}:$ : cat pglF iga::pilA ${ }_{F n}$ & This study \\
\hline KS144 & pglI::kan & Aas et al. (2007b) \\
\hline KS190 & recA $($ tetM $)$ pil $_{G C}:$ : cat pglI:: kan iga:: pilA $A_{F t}$ & This study \\
\hline KS191 & recA $\left(\right.$ tetM) pilE $E_{G C}:$ : cat pglI:: kan iga::pilA Fn & This study \\
\hline KS145 & pglO:: kan & Aas et al. (2007b) \\
\hline KS192 & recA $\left(\right.$ tetM) pilE $E_{G C}:$ :cat pglO:: kan iga: : pilA ${ }_{F t}$ & This study \\
\hline KS193 & recA (tetM) pilE ${ }_{G C}:$ :cat pglO:: kan iga:: pilA $F n$ & This study \\
\hline \multicolumn{3}{|c|}{ 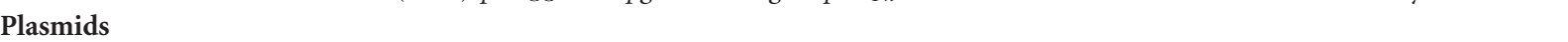 } \\
\hline pCR2.1-TOPO & TOPO-cloning vector, $\mathrm{Amp}^{\mathrm{R}} \mathrm{Km}^{\mathrm{R}}$ & Invitrogen \\
\hline pCRII-TOPO & TOPO-cloning vector, $\mathrm{Amp}^{\mathrm{R}} \mathrm{Km}^{\mathrm{R}}$ & Invitrogen \\
\hline pCR4.0-TOPO & TOPO-cloning vector, $\mathrm{Amp}^{\mathrm{R}} \mathrm{Km}^{\mathrm{R}}$ & Invitrogen \\
\hline pUP6 & pSSH6 plasmid with gonococcal uptake sequence & Wolfgang et al. (1999) \\
\hline $\mathrm{p} 2 / 16 / 1$ & $\begin{array}{l}\text { pUP6 plasmid carrying the gene encoding IgA1 protease and } \\
\text { an erythromycin-resistance cassette }\end{array}$ & Wolfgang et al. (2000) \\
\hline pPilE2 & p2/16/1iga::pilE $E_{G C}, \mathrm{Km}^{\mathrm{R}}$ & Aas et al. (2006) \\
\hline pEMS25 & $\mathrm{p} 2 / 16 / 1$ iga: : pilA $A_{F}, \mathrm{Km}^{\mathrm{R}}$ & This study \\
\hline pEMS26 & $\mathrm{p} 2 / 16 / 1$ iga::pilE $E_{F t}, \mathrm{Km}^{\mathrm{R}}$ & This study \\
\hline pEMS27 & $\mathrm{p} 2 / 16 / 1$ iga: : pilV $V_{F}, \mathrm{Km}^{\mathrm{R}}$ & This study \\
\hline pEMS28 & p2/16/1iga:: FTT0861 $\mathrm{Ft}, \mathrm{Km}^{\mathrm{R}}$ & This study \\
\hline pEMS29 & p2/16/1iga:: FTT0230 $\mathrm{Ft}, \mathrm{Km}^{\mathrm{R}}$ & This study \\
\hline
\end{tabular}


Table 1. cont.

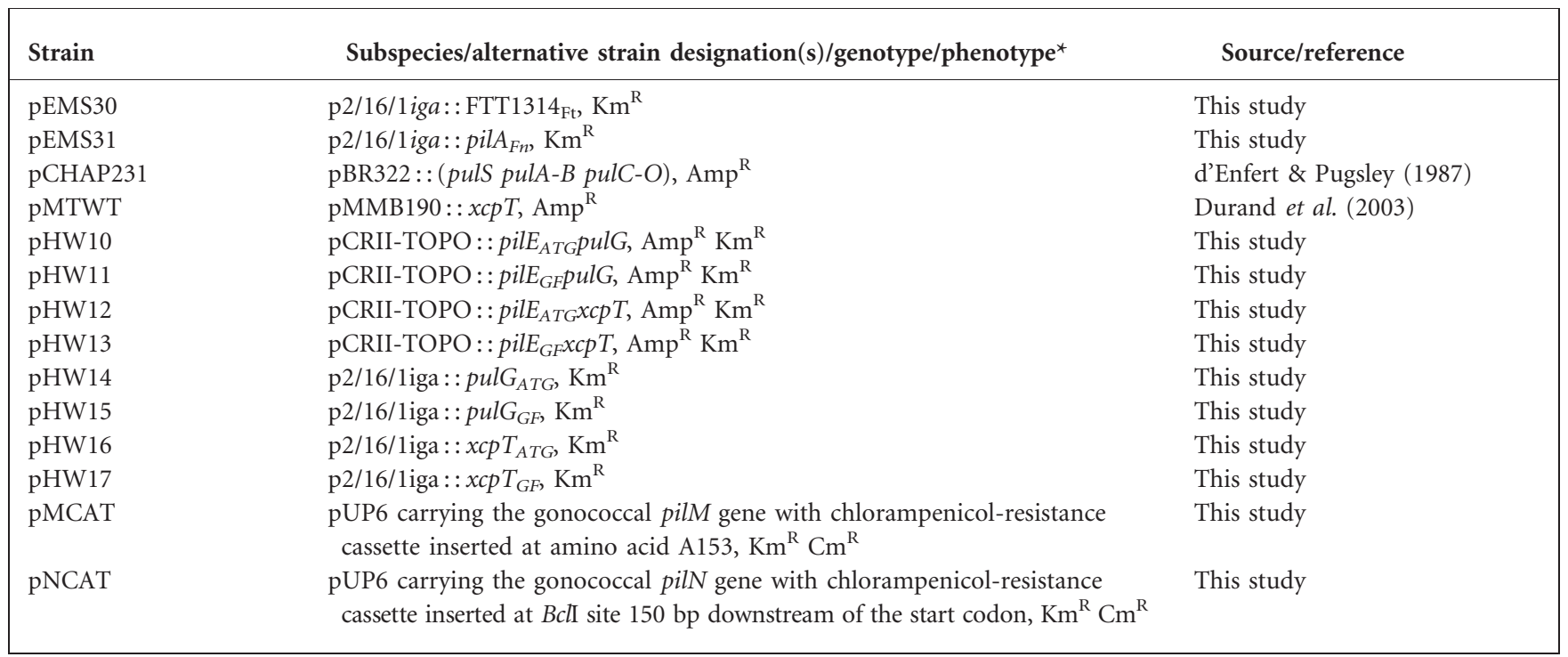

${ }^{\star} \mathrm{Amp}^{\mathrm{R}}$, ampicillin resistance marker; $\mathrm{Km}^{\mathrm{R}}$, kanamycin resistance marker; $\mathrm{Cm}^{\mathrm{R}}$; chloramphenicol resistance marker.

$\dagger$ All Francisella strains are from the Francisella Strain Collection at FOI, Umeå, and each strain has been given a strain collection number (FSC). ¥The Francisella subsp. novicida pilA gene (FTN_0415) has been denoted pilA $A_{F n}$.

pilins between subsp. tularensis and subsp. holarctica (Fig. 1a). One locus containing three tandemly arrayed putative prepilin genes $\left(p i l A_{F t}, p i l E_{F t}\right.$ and $\left.p i l V_{F t}\right)$ is rearranged in some avirulent subsp. holarctica strains, including the live vaccine strain (Forslund et al., 2006; Svensson et al., 2005). These rearrangements are associated with an in-frame deletion spanning the pilA $F t$ gene and the N-terminalencoding part of pilE $E_{F t}$ (Svensson et al., 2005).
Furthermore, the residual pilE $F t$ and pilV $V_{F t}$ genes are predicted to be pseudogenes in subsp. holarctica due to non-sense mutations (Fig. 1a). In addition, internal deletions and a mutation within the stop codon change the reading frame of FTT0861 $1_{\mathrm{Ft}}$ (Larsson et al., 2005) (Fig. 1a), thereby extending the ORF in subsp. holarctica. The two remaining prepilin-like ORFs, FTT0230 $0_{\mathrm{Ft}}$ and FTT1314 $4_{\mathrm{Ft}}$, are identical between subspp. tularensis and holarctica.

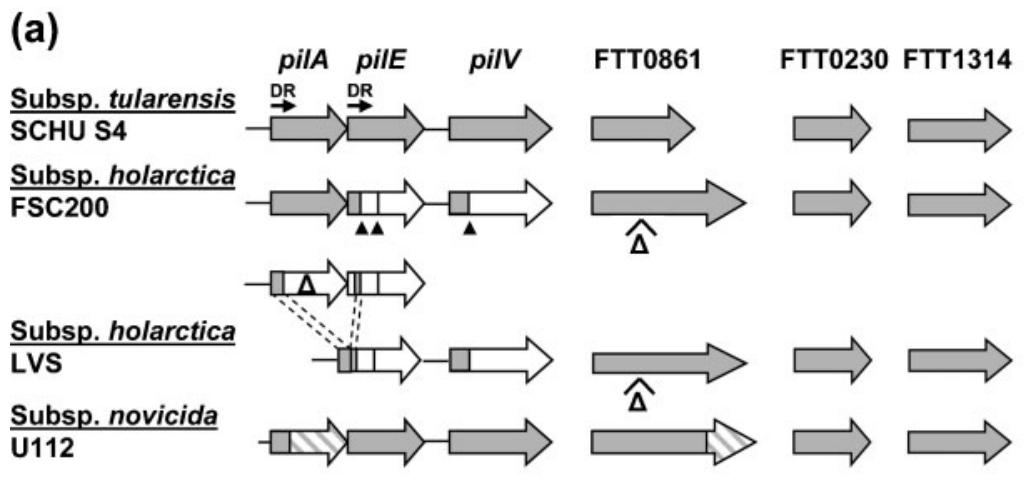

(b)

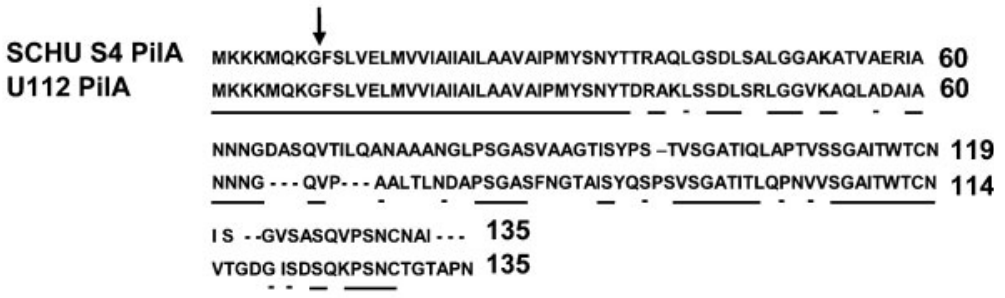

Fig. 1. Comparison of gene clusters encoding putative Tfp pilins in F. tularensis subspecies tularensis, holarctica and novicida. (a) All $F$. tularensis subspecies have direct repeats (DRs) within the $\mathrm{N}$-terminal part of the pil $A_{F t}$ and pilE $E_{F t}$ genes (solid arrows). In some subsp. holarctica strains, the DRs have mediated deletion of the pil $A_{F t}$ gene. pil $E_{F t}$ and pil $V_{F t}$ are not functional in subsp. holarctica due to non-sense mutations (arrowheads), and the FTT0861 $\mathrm{Ft}$ pilin gene has an altered and extended reading frame due to a deletion event ( $\Delta$ signs) causing mutations within the stop codon. (b) Alignment of the amino acid sequences of $F$. tularensis subsp. tularensis $\mathrm{PilA}_{\mathrm{Ft}}$ and subsp. novicida PilA $\mathrm{Fn}_{\mathrm{Fn}}$. The $\mathrm{N}$ terminal 36 amino acids are identical while there are significant differences in the Cterminal part of these proteins. The solid arrow indicates the cleavage site of the prepilin. 
Within the genome of subsp. novicida strain U112 (Rohmer et al., 2007), most of the Tfp-related genes are found to be similar to the Tfp genes in the highly virulent subsp. tularensis strain SCHU S4. However, one prominent difference is in the F. tularensis equivalent pilA, pilE and pilV gene cluster. Here, the C-terminal half of the first gene, pilA $A_{F n}$ (FTN_0415), is significantly different, while the $\mathrm{N}$-terminal part remains homologous to SCHU S4 pilA $F$ (Fig. 1b). In addition, some sequence differences are also seen in the intergenic regions of the pilAEV $V_{F n}$ cluster (Forsberg \& Guina, 2007).

\section{Expression of Francisella Tfp-like pilins in N. gonorrhoeae}

Owing to the conservation and promiscuity of the biogenesis machineries, expression of Tfp pilins in heterologous species has been successfully used to analyse pilus structure-function relationships (Elleman et al., 1986; Hoyne et al., 1992; Sauvonnet et al., 2000; Winther-Larsen et al., 2007). Here, we examined the propensities for the putative Francisella pilins to form Tfp in the heterologous Tfp expression system of $N$. gonorrhoeae, conditionally lacking the endogenous pilin subunit PilE (also denoted here as $\mathrm{PilE}_{\mathrm{GC}}$ ). To avoid potential problems related to heterologous expression levels, the Francisella pilin ORFs from subsp. tularensis strain SCHU S4 and pilA $F n$ from subsp. novicida strain U112 were fused so as to create a glycine-phenylalanine junction to $\mathrm{PilE}_{\mathrm{GC}}$. Thus, the resulting translational fusion proteins carried the first seven residues of PilE $E_{G C}$, but when processed by the PilD prepilin peptidase, the mature proteins are predicted to be entirely Francisella-derived. Despite repeated efforts, a translational fusion encoding the subsp. tularensis pilin FTT1314 $4_{\mathrm{Ft}}$ could not be obtained in $N$. gonorrhoeae due to accumulation of spontaneous mutations following transformation into $N$. gonorrhoeae. Immunoblot analysis verified that the remaining pilins, except for $\mathrm{FTT} 0861_{\mathrm{Ft}}$, were expressed in the N. gonorrhoeae background (Fig. 2). Direct sequencing from genomic DNA, however, verified that the FTT0861 $1_{\mathrm{Ft}}$ clone was correct. All other pilins migrated as expected based on their calculated molecular masses, and the relative intensities of the signals varied between the antibody probes. The anti-PilE $\mathrm{GC}_{\mathrm{GC}}$ antibodies were raised against the pilin subunits isolated from N. gonorrhoeae strain N400, and in a previous study it was suggested that the ability of heterologous Tfp antibodies to detect pilin subunits in immunoblotting involves exposure of a highly conserved epitope within or near the mature $\mathrm{N}$-terminus following PilD cleavage (Patel et al., 1991). The PilA $\mathrm{Ft}_{\mathrm{Ft}}$ antibody was raised against the $\mathrm{C}$-terminal part of the PilA $\mathrm{A}_{\mathrm{Ft}}$ protein (Forslund et al., 2006). Hence, this antibody is specific for the Pil $\mathrm{A}_{\mathrm{Ft}}$ pilin and would not recognize other pilins.

\section{PilA from F. tularensis subsp. tularensis and subsp. novicida supports formation of Tfp-like structures in N. gonorrhoeae}

As a first approach, transmission electron microscopy (TEM) was used to examine if the putative Francisella

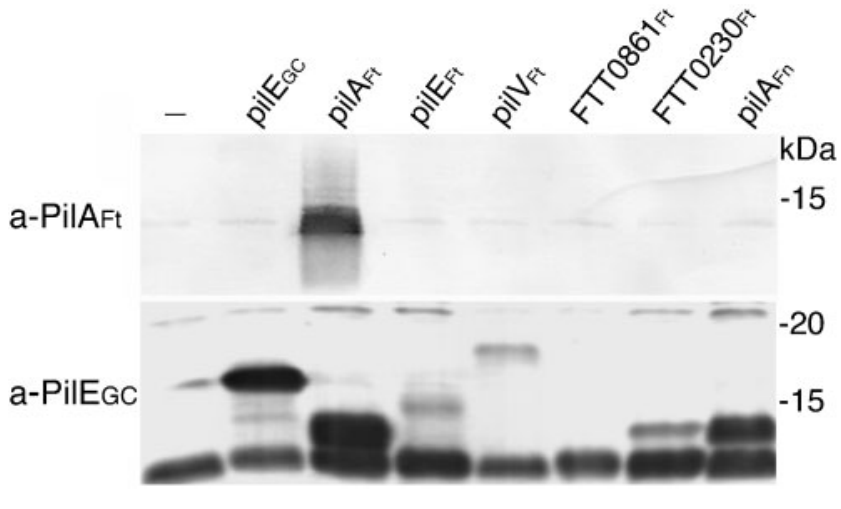

Fig. 2. Expression of putative Francisella pilin genes in $N$. gonorrhoeae. Total bacterial lysates were separated by SDSPAGE under denaturing conditions and proteins were identified by immunoblotting using anti-Pil $\mathrm{A}_{\mathrm{Ft}}$ (upper panel) or anti-PilE $\mathrm{E}_{\mathrm{GC}}$ (lower panel) antibodies. Strains used (lanes from left): MW24 (pilE $\left.E_{G C}\right) ; \quad$ GE2 (iga::pilE $\left.E_{G C}\right), \quad$ KS59 (iga::pilA $A_{F t}$ ), KS60 (iga: : pil $E_{F t}$ ), KS61 (iga:: pilV $\left.V_{F t}\right)$, KS62 (iga::FTT0861 $1_{\mathrm{Ft}}$ ), KS63 (iga: : FTT0230 ${ }_{\mathrm{Ft}}$ ), KS64 (iga: : pilA $A_{F n}$ ).

pilins could form pilus-like filaments in $N$. gonorrhoeae. Structures resembling Tfp were only observed for the $\mathrm{PilA}_{\mathrm{Fn}^{-}}$ expressing strain (KS64) (Fig. 3) and at levels well below those seen for endogenous Tfp. In addition, these structures appeared as single filaments compared to the pilus bundles usually observed for wild-type gonococcal cells. Next, surface exposure of the pilin-like proteins was examined by immunofluorescence microscopy (IFM) using antibodies shown to be reactive in immunoblotting. Although no immunolabelling was detected using rabbit antibodies raised against $\mathrm{PilA}_{\mathrm{Ft}}$, antibodies raised against wild-type pili from N. gonorrhoeae strain N400 revealed the presence of Tfp-like appendages in strains expressing either PilA $\mathrm{Fn}_{\mathrm{Fn}}$ (KS64) or PilA $_{\mathrm{Ft}}$ (KS59) (Fig. 4a). No immunoreactive filaments were detected in the strains expressing $\mathrm{PilE}_{\mathrm{Ft}}(\mathrm{KS60})$, PilV $\mathrm{Ft}$ $(\mathrm{KS} 61), \mathrm{FTT} 0861_{\mathrm{Ft}}(\mathrm{KS} 62)$ or FTT0230 $0_{\mathrm{Ft}}(\mathrm{KS} 63)$ (Table 2 and IFM not shown). The immunoreactive filaments seen using the N400 Tfp antiserum in cells expressing PilA $\mathrm{A}_{\mathrm{Fn}}$ and PilA $_{\mathrm{Ft}}$ differed from those seen in the wild-type $N$. gonorrhoeae background. First, the numbers of fluorescent appendages were considerably fewer in the Francisella PilAexpressing backgrounds (Table 2). Second, the appendages were longer than the short pilus bundles observed in the wild-type background. To determine if the filaments seen for Francisella PilA by IFM were directly related to those detected by TEM, immunogold-labelling TEM using the N400 PilE $E_{\mathrm{GC}}$ antiserum was carried out. As the appendages were specifically decorated with gold particles (Fig. 4b), we propose that the structures observed by TEM are the same as those detected by IFM.

In an attempt to confirm the composition of the structures seen for the PilA $\mathrm{Ft}_{\mathrm{Ft}}$ and PilA $\mathrm{Fn}$ backgrounds, we carried out standard pilus purification schemes (Winther-Larsen et al., 2007; Wolfgang et al., 1998a). However, no pili were 

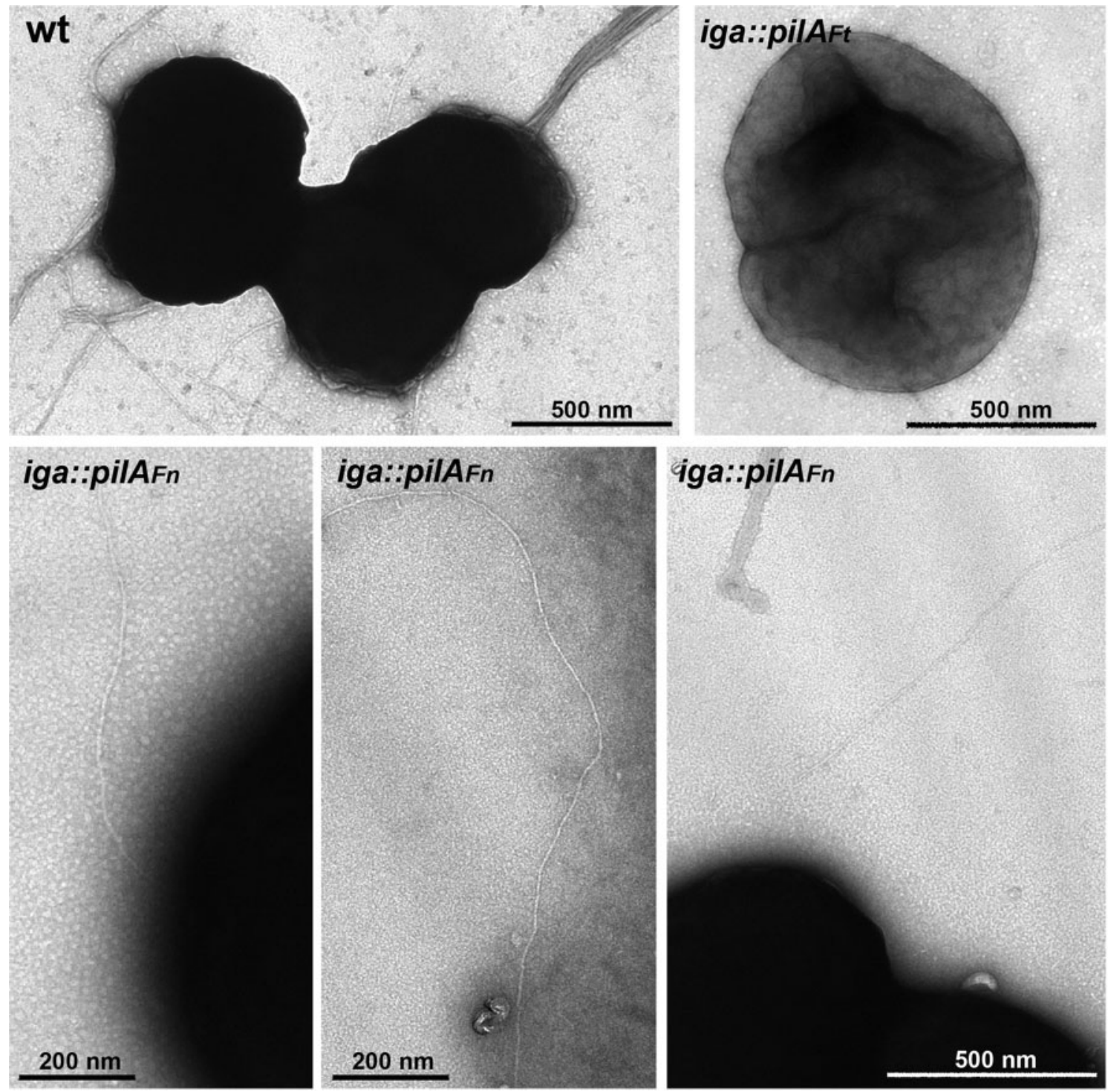

Fig. 3. Piliation of wild-type and mutant gonococcal strains expressing pilA from Francisella subsp. tularensis and subsp. novicida, analysed by negative-stained TEM. Strains: GE2 (wt, iga : : pil $E_{G C}$ ); KS59 (iga : : pil $A_{F t}$ ) and KS64 (iga : : pilA $\left.A_{F n}\right)$.

recovered using these protocols. It has previously been demonstrated that levels of detectable $P$. aeruginosa

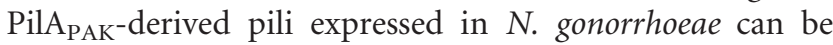
dramatically increased in a mutant background lacking the PilT retraction ATPase (Winther-Larsen et al., 2007). However, the use of this background in these instances had no influence on the levels of appendages detected by IFM, TEM or purification attempts (Supplementary Figs S1 and S2 and data not shown, respectively).

\section{Evidence for Francisella PilA protein glycosylation in $\mathbf{N}$. gonorrhoeae}

Although epitope sharing between unrelated Tfp pilins has been documented in Western-type immunoblotting experi- ments using heterologous anti-Tfp antisera, it seemed curious that antibodies to strain N400 Tfp would react with the $\mathrm{PilA}_{\mathrm{Fn}^{-}}$and $\mathrm{PilA}_{\mathrm{Ft}}$-associated surface structures in $N$. gonorrhoeae. A recent study documented that immunization of rabbits with endogenous N400 Tfp results in antibodies that recognize epitopes associated with the galactose-2,4diacetamido-2,4,6-trideoxyhexose (Gal-DATDH) disaccharide linked at serine 63 of $\mathrm{PilE}_{\mathrm{GC}}$ (Vik et al., 2009). There is also indirect evidence that $\mathrm{PilA}_{\mathrm{Ft}}$ is post-translationally modified in its endogenous host (Forslund et al., 2006). To determine if PilA $_{\mathrm{Ft}}$ and PilA $\mathrm{Fn}$ might be O-glycosylated in N. gonorrhoeae, we examined the relative motilities of the proteins in defined $N$. gonorrhoeae protein glycosylation $(p g l)$ mutants and variants (Aas et al., 2007a). Null mutations in core genes essential for protein glycosylation ( $p g l C, p g l D, p g l F$ and $p g l O)$ 
(a)
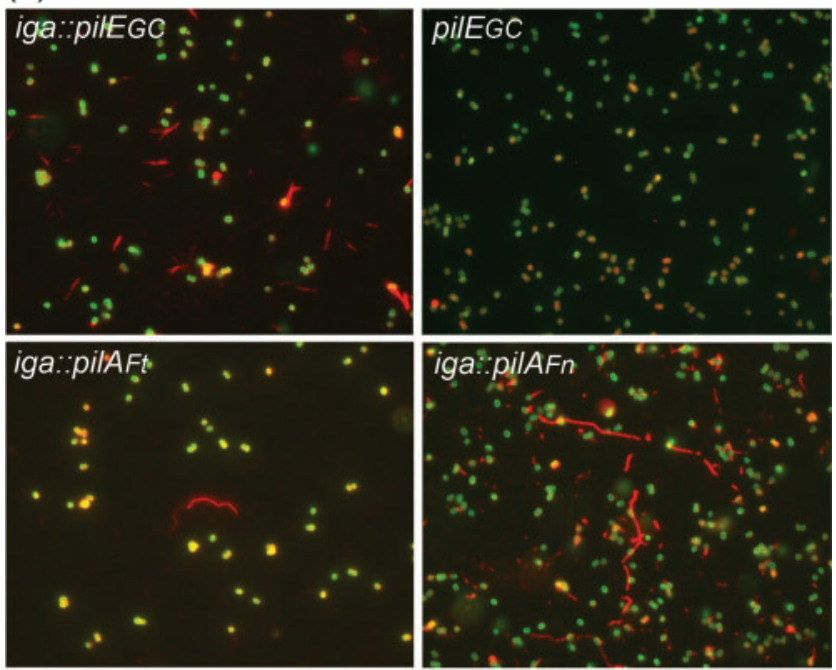

(b)

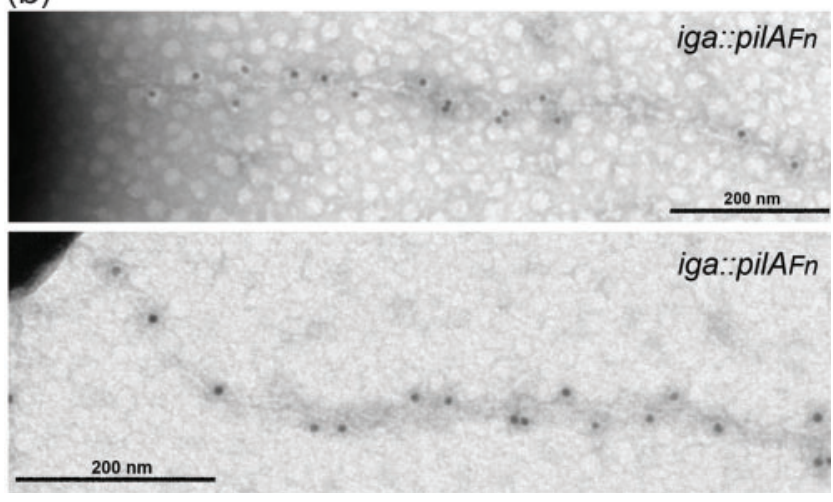

Fig. 4. IFM of $N$. gonorrhoeae expressing various pilin genes from F. tularensis. Gonococcal cells (green) and Tfp-like structures (red) were detected using indirect IFM. Anti-PilE $E_{G C}$ specific antibodies (lot 904) were used to detect the Tfp-like structures. Strains: GE2 (iga::pil $E_{G C}$ ), MW24 (pil $E_{G C}$ ), KS59 (iga: : pil $A_{F t}$ ) and KS64 (iga::pil $A_{F n}$ ). Note that the appearance of Tfp seen here is quite similar to that seen using the same type of technique for E. coli cells expressing the PulG pseudopilus as bundles (Vignon et al., 2003). (b) Piliation of gonococcal strain KS64 (iga: : pil $A_{F n}$ ) detected by immunogold labelling and TEM using anti-PilE $E_{G C}$ (lot 904) antibodies (10 nm gold particles).

in N. gonorrhoeae were associated with an increase in PilA $A_{F n}$ migration, while in a pglA mutant background in which only the DATDH monosaccharide is linked to proteins, the migration was intermediate between that seen in the wildtype and null mutants (Fig. 5a). Furthermore, dramatically retarded migration was observed in a $p g l E_{O N}$ variant background in which a Gal-Gal-DATDH trisaccharide is linked to proteins. Virtually identical results were seen for the behaviour of Pil $\mathrm{Ft}_{\mathrm{Ft}}$, with the exception of the $p g l E_{\mathrm{ON}}$ variant background, in which four distinct antigenic forms migrating more slowly than the form seen in the glycosylation null mutants were detected. Taken together, these findings suggest that Francisella PilA proteins undergo glycosylation in $N$. gonorrhoeae. We then tested the potential influence of protein glycosylation on the ability of the antibodies to react with the PilA-associated appendages by IFM. For both the Francisella $\mathrm{PilA}_{\mathrm{Fn}}$ and PilA $\mathrm{At}_{\mathrm{Ft}}$ proteins, the glycosylation null mutation $p g l C$ abrogated the labelling of the structures (Fig. 5b). However, the absence of PglC did not affect surface organelle expression, as Tfp-like structures were still visible by TEM in the PilA $\mathrm{Fn}_{\text {-expressing }}$ pglC mutant strain (Fig. 5c).

\section{PilA from F. tularensis subsp. tularensis and subsp. novicida supports competence for natural genetic transformation in $\mathbf{N}$. gonorrhoeae}

It has previously been demonstrated that the expression of $P$. aeruginosa pilin PilA $\mathrm{PAK}_{\mathrm{P}}$ can partially complement a defect in competence for natural transformation in a gonococcal strain lacking its endogenous pilin (Aas et al., 2002). Using the same strategy, we examined whether Francisella pilins could function in competence for transformation in an otherwise unpiliated $N$. gonorrhoeae background. Only the strain expressing PilA $\mathrm{Fn}_{\mathrm{n}}$ from subsp. novicida (KS72) supported transformation levels just above that seen for the unpiliated control strain (Table 2). It should be noted that compared to growth on plates, strains expressing PilV $\mathrm{Ft}_{\mathrm{Ft}}$ (KS69) and pilin FTT0230 Ft $_{\text {(KS71) grew }}$ poorly in liquid culture, a property which may have a negative impact on the transformation phenotype for these strains. In a study by Aas et al. (2002), two pilin-like proteins, $\mathrm{ComP}_{\mathrm{GC}}$ and $\mathrm{PilV}_{\mathrm{GC}}$, were shown to influence the transformation levels, but not Tfp expression, in $N$. gonorrhoeae. Whereas $\mathrm{ComP}_{\mathrm{GC}}$ is essential for natural transformation, and its elevated expression leads to enhanced transformation frequencies, PilV $\mathrm{V}_{\mathrm{GC}}$ inhibits transformability by antagonizing ComP function. As such, pil $V_{G C}$ mutants phenocopy ComP-overexpressing strains $\left(\operatorname{comP} P_{o e}\right)$. When tested in $N$. gonorrhoeae comP $P_{o e}$ or pilV $V_{G C}$ backgrounds, the expression of PilA $\mathrm{Fn}$ led to an over 500fold increase in transformation frequency (Table 2). PilA $A_{F t}$ expression also led to an increase in transformability, but at more modest levels (20-40-fold). None of the other four Francisella pilins altered transformability in either of the two backgrounds. As noted previously, the expression of both PilV $\mathrm{Ft}_{\mathrm{Ft}}(\mathrm{KS75}, \mathrm{KS} 83)$ and FTT0230 $\mathrm{Ft}$ (KS77, KS85) was associated with poor growth in liquid culture, which could potentially also affect the results here.

The three sets of transformation experiments described above were all conducted in a genetic background where the expression of the endogenous gonococcal pilin was under the control of the lac promoter, although noninduced. Studies have shown that very low levels of PilE $\mathrm{GC}$ are sufficient for high-level transformability (Aas et al., 2007b; Long et al., 2001). Therefore, it was possible that physiological alterations associated with high-level expression of Francisella pilins might perturb levels of LacI repressor, allowing residual expression of $\mathrm{PilE}_{\mathrm{GC}}$. To address this concern, the $\mathrm{PilA}_{\mathrm{Fn}^{-}}$and $\mathrm{PilA}_{\mathrm{Ft}}$-expressing 
Table 2. Francisella PilA pilin supports genetic transformation but not twitching motility in N. gonorrhoeae

\begin{tabular}{|c|c|c|c|c|c|c|}
\hline Relevant genotype & Piliation $(\%)^{\star}$ & $\dagger$ & $\operatorname{com} P_{o \notin} \ddagger$ & $p_{i l V_{G C}} \S$ & $\begin{array}{c}\operatorname{pilV}_{G C} \\
\operatorname{pil}_{G C}:: c a t \|\end{array}$ & $\begin{array}{c}\text { Twitching } \\
\text { motility } \dagger\end{array}$ \\
\hline- & 0 & $<0.001$ & $<0.001$ & $<0.001$ & $<0.001$ & - \\
\hline iga:: pil $E_{G C}$ & $28 \pm 12$ & $8.21 \pm 4.8$ & $25.5 \pm 12$ & $27.9 \pm 9.5$ & $26 \pm 3.5$ & + \\
\hline iga::pil $V_{F t}$ & 0 & $<0.001$ & $<0.001$ & $<0.001$ & ND & - \\
\hline iga::FTT0861 $1_{\mathrm{Ft}}$ & 0 & $<0.001$ & $<0.001$ & $<0.001$ & $<0.001$ & - \\
\hline iga: :FTT0230 $\mathrm{Ft}$ & 0 & $<0.001$ & $<0.001$ & $<0.001$ & $\mathrm{ND}$ & - \\
\hline iga::pilA ${ }_{F n}$ & $9 \pm 6$ & $0.003 \pm 0.001$ & $2.24 \pm 0.5$ & $0.86 \pm 0.25$ & $1.42 \pm 0.4$ & - \\
\hline iga::pul $G_{G F}$ & $\mathrm{ND}$ & $<0.001$ & ND & $<0.001$ & $\mathrm{ND}$ & ND \\
\hline
\end{tabular}

ND, Not determined.

${ }^{\star}$ Piliation detected by IFM from at least five sets of experiments. Percentage calculated by counting the number of pili per 600 gonococcal cells (strains: KS101, GE101, KS67-KS72).

$\dagger$ Determined for N. gonorrhoeae strains with pilE $E_{G C}$ under the control of an inducible promoter (strains: KS101, GE101, KS67-KS72, KS167$\mathrm{KS} 170)$. pilE $\mathrm{E}_{\mathrm{GC}}$ was not induced during the experiments.

$\ddagger$ Same as $\dagger$, but carried out in a ComP-overexpressed background (strains: GP111, GP122, KS73-KS78).

$\$$ Same as $\dagger$, but carried out in a pilV $V_{G C}$ mutant background (strains: KS79-KS86, KS171-KS174).

$\|$ Same as $\$$, but with pilE $E_{G C}$ mutated by insertion of a chloramphenicol-resistance cassette (strains: KS44, KS87-KS90, KS175, KS199).

pil $V_{G C}$ strains were re-engineered so that the inducible pil $_{G C}$ allele was disrupted by a chloramphenicol-resistance gene cassette (Hegge et al., 2004). The transformation frequency was essentially unaltered in this background compared to the pilV $V_{G C}$ inducible pilE $E_{G C}$ parent strains (Table 2) proving that residual PilE $_{\mathrm{GC}}$ expression could not account for the enhanced transformation frequencies.

As dynamic polymers, Tfp undergo rounds of extension and retraction events that are commonly a prerequisite for Tfp-associated genetic transformation (Wolfgang et al., 1998a). In N. gonorrhoeae, the ability to undergo twitching motility on surfaces is directly correlated with pilus retraction activity (Merz et al., 2000). However, none of the Francisella pilins supported twitching motility when assessed by microscopic examination for movement at the periphery of colonies or by the slide culture method (Table 2).

\section{Expression of the T2SS pseudopilin XcpT from $P$. aeruginosa or PulG from $K$. oxytoca does not support genetic transformation in $\mathbf{N}$. gonorrhoeae}

Both the transformation and microscopy data noted above support the hypothesis that $\mathrm{PilA}_{\mathrm{Ft}}$ and $\mathrm{PilA}_{\mathrm{Fn}}$ are $\mathrm{Tfp}$ pilins. It is important to note, however, that T2SS proteins of the PulG family can, when overexpressed, result in the formation of pseudopili with an appearance similar to Tfp
(Durand et al., 2003; Vignon et al., 2003). Few studies, if any, have explored whether the expression of T2SS pseudopilins can support Tfp-associated functions. To examine this possibility in more detail, the T2SS proteins PulG and XcpT from $K$. oxytoca and P. aeruginosa, respectively, were cloned and expressed in $N$. gonorrhoeae. Like the Francisella pilins, both were fused at the prepilin peptidase processing site in addition to fusions generated at the putative ATG translational start codons. The expression of both PulG and XcpT in N. gonorrhoeae was verified using antibodies specific for each protein (Supplementary Fig. S3). The transformation assay revealed that neither PulG nor XcpT supported genetic transformation in $N$. gonorrhoeae in either a wild-type or pil $V_{G C}$ mutant background (Table 2). Moreover, no piluslike filamentous structures could be detected by TEM (data not shown).

\section{Expression of Francisella PilA-associated appendages depends on Tfp biogenesis factors}

The expression of Tfp depends on several canonical Tfp assembly factors (Carbonnelle et al., 2006; Martin et al., 1995; Nudleman et al., 2006) that are unique to Tfp systems as they are lacking in T2SSs. We expressed both $\mathrm{PilA}_{\mathrm{Ft}}$ and $\mathrm{PilA}_{\mathrm{Fn}}$ in a selection of mutant backgrounds lacking such components, including $\mathrm{PilF}_{\mathrm{GC}}, \mathrm{PilM}_{\mathrm{GC}}$ or PilN $_{\mathrm{GC}}$, to investigate whether the Francisella-associated 


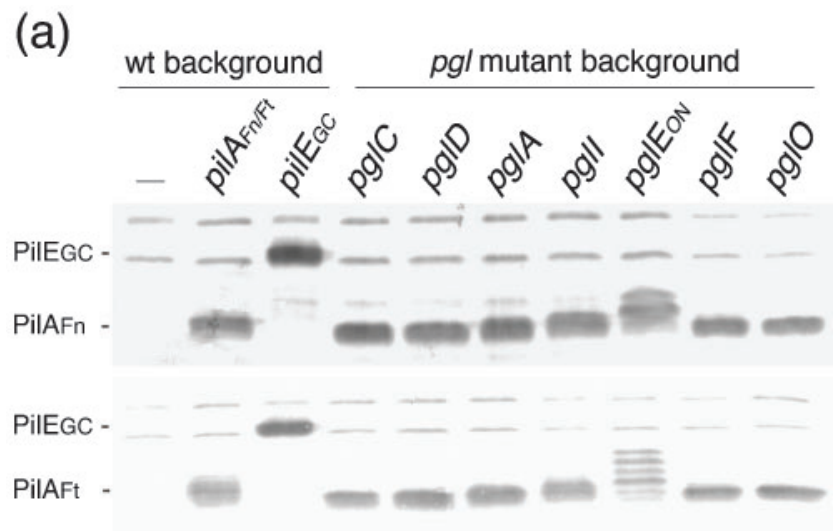

(b)
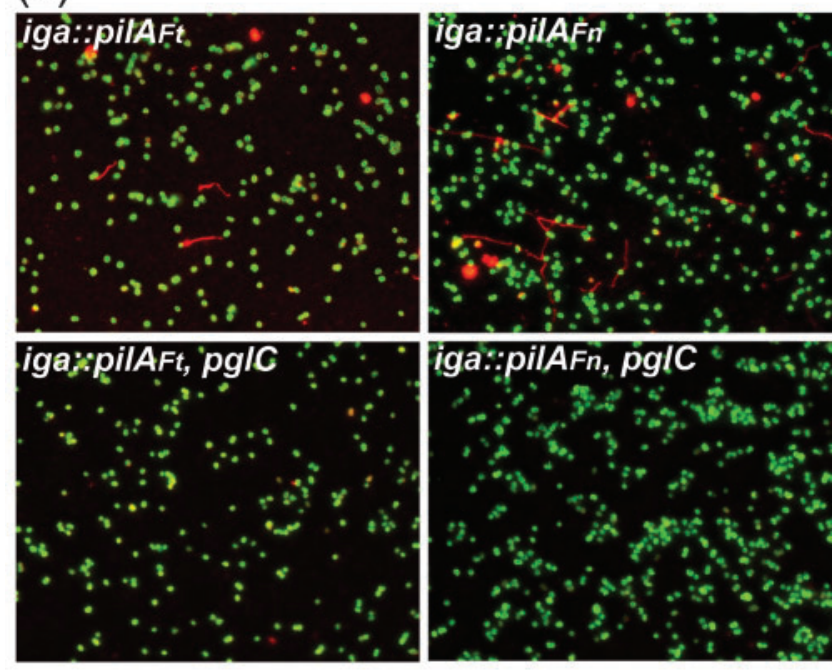

(C) iga::pilAFn, pg/C

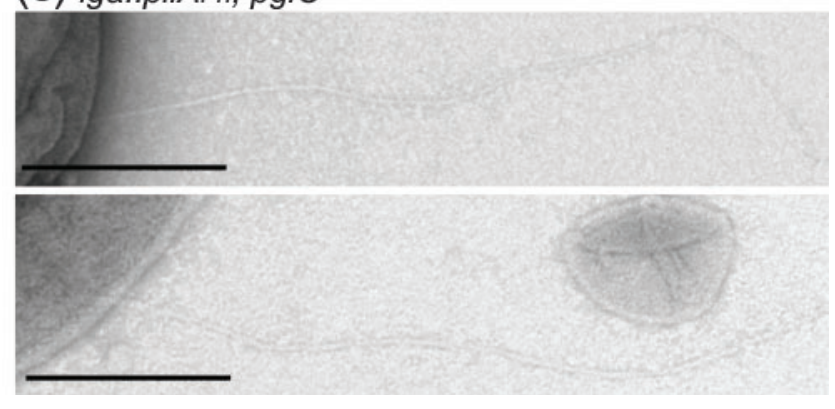

filament requires the endogenous $N$. gonorrhoeae Tfp assembly machinery. PilM $\mathrm{GC}_{\mathrm{GC}}$ and PilN $\mathrm{NC}_{\mathrm{GC}}$ are Tfp assembly factors that act in unknown capacities (Carbonnelle et al., 2006), while $\mathrm{PilF}_{\mathrm{GC}}$ (PilB in P. aeruginosa) is believed to be the subunit polymerization ATPase (O'Toole \& Kolter, 1998). Pilus expression was abolished in all three biogenesis-defective mutant backgrounds (Supplementary Fig. S4).
Fig. 5. Influence of the $N$. gonorrhoeae glycosylation mutants on $\mathrm{Pil}_{\mathrm{Ft}}$ and Pil $A_{\mathrm{Fn}}$. (a) Influence on relative migration of Pil $A_{\mathrm{Ft}}$ and Pil $A_{F n}$. Immunoblot of whole-cell lysates using anti-Pil $A_{P A K}$ antibodies. The strains used were as follows. Upper panel: first lane MW24 (pil $E_{G C}$ ), and then iga::pilA $A_{F n}(K S 64)$, iga:: pilE $E_{G C}$ (GE2), pg/C (KS183), pg/D (KS185), pglA (KS181), pgll (KS191), pglE $E_{\mathrm{ON}}$ (KS187), pglF (KS189), pglO (KS193). Lower panel: first lane MW24 (pil $E_{G C}$ ), and then iga:: pil $A_{F t}(K S 59)$, iga:: pilE $E_{G C}$ (GE2), pglC (KS182), pglD (KS184), pglA (KS180), pgll (KS190), $p g / E_{\mathrm{ON}}(\mathrm{KS} 186), p g / F$ (KS188), pg/O (KS192). (b) Influence on the cross-reactivity of Francisella PilA pilins with anti-PilE $\mathrm{GC}_{\mathrm{GC}}$ antibodies (lot 904). Gonococcal cells (green) and Tfp-like structures (red) were detected using indirect IFM. Strains: iga:: pilA $A_{F t}$ (KS59), iga::pil/ $A_{F t}$ pglC (KS182), iga::pilA $A_{F n}$ (KS64), iga:: pil $A_{F n}, p g / C$ (KS183). Note that the appearance of Tfp seen here is quite similar to that seen using the same type of technique for $E$. coli cells expressing the PulG pseudopilus (Vignon et al., 2003). (c) Piliation analysis by negative-stained TEM of strain iga: : pil/ $A_{F n}, p g / C$ (KS183). Scale bars, $200 \mathrm{~nm}$.

\section{DISCUSSION}

As previously shown, homologues of Tfp structural and biogenesis components influence the pathogenesis of $F$. tularensis subsp. holarctica and subsp. novicida infections (Forslund et al., 2006; Zogaj et al., 2008). There are clear polymorphisms and gross differences in the content of genes encoding these components that correlate with the relative virulence of Francisella species (Forslund et al., 2006). However, there remains a large gap in our knowledge of how these components function in shaping pathogenic potential. With the aim of beginning to resolve these issues, we conducted trans-species complementation studies and found that one particular class of pilin-like proteins in subspp. tularensis and novicida can complement Tfp-related features and functions in a strain of $N$. gonorrhoeae lacking its endogenous pilin. Despite their orthologous nature, however, PilA $\mathrm{Ft}_{\text {and }} \mathrm{Pil} \mathrm{A}_{\mathrm{Fn}}$ behaved differently in this background. While expression of both pilins individually was associated with the expression of Tfp-like appendages detectable by IFM, the levels of the appendages were lower in the $\mathrm{PilA}_{\mathrm{Ft}}$-expressing strain. Consistent with these differences, TEM detected Tfp-like organelles only in the $\mathrm{PilA}_{\mathrm{Fn}}$-expressing strain. These findings were paralleled by dramatic differences in the abilities of these two pilin-like proteins to support competence for natural genetic transformation. In backgrounds optimized to enhance DNA binding and uptake, transformability in the $\mathrm{PilA}_{\mathrm{Fn}}$-expressing strain was increased nearly 1000 -fold relative to the negative control background and 50-fold relative to the isogenic $\mathrm{PilA}_{\mathrm{Ft}^{-}}$ expressing strain. Interestingly, competence for transformation has been reported for subsp. novicida (Gallagher et al., 2008; Tyeryar \& Lawton, 1970). The significance of this results in relation to our data is difficult to interpret since the components required for DNA uptake in subsp. novicida have yet to be characterized. It is 
important to note here that all available data back the notion that transformability in $N$. gonorrhoeae absolutely requires an intact Tfp extension/retraction system including a major pilin subunit (Wolfgang et al., 1998a). We hypothesize accordingly that the appendages seen by IFM and TEM are in fact filamentous polymers made up of PilA $_{\text {Fn }}$ and are structural equivalents of bona fide Tfp. This proposal is supported by the fact that antibodies raised against endogenous $\mathrm{Tfp}$ (composed of $\mathrm{PilE}_{\mathrm{GC}}$ ) that detect PilA $_{\text {Fn }}$ protein in immunoblotting also react with the

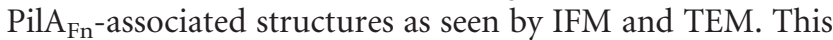
proposal is further backed by the observations that these structures are not seen in cells individually lacking PilM $\mathrm{GC}_{\mathrm{GC}}$, PilN $\mathrm{N}_{\mathrm{GC}}$ and $\mathrm{PilF}_{\mathrm{GC}}$, which are associated specifically with the Tfp assembly system, as they have no counterparts in related T2SSs.

A shortcoming in determining if the structures seen in gonococci are $\mathrm{Tfp}$ has been the inability to purify the appendages and characterize their composition. This same situation confounds previous studies examining the relationships between Tfp-related components and the expression of extracellular appendages in both $F$. tularensis subsp. holarctica and subsp. novicida. Zogaj et al. (2008) identified pilus-like appendages in subsp. novicida and also studied the presence or absence of these structures in a variety of mutant backgrounds. Based on indirect genetic data, the authors proposed that PilE4 (orthologous to what is termed FTT0861 in this work) is the major structural subunit of Tfp. Somewhat surprisingly, the appendages were seen independently of the expression of homologues of the PilQ secretin and PilC inner-membrane protein families $(P$. aeruginosa nomenclature) that are essential for Tfp expression in most species. Similar studies of the live vaccine strain, LVS (subsp. holarctica), have concluded that this strain also expresses Tfp-like structures (Chakraborty et al., 2008). It is difficult to assess the potential relevance/ applicability of our results to the work with the LVS, as that strain carries a mutation that inactivates expression of PilA $_{\mathrm{Ft}}$, the pilin-like protein we examined. In the case of subsp. novicida, however, our findings increase the possibility that PilA $\mathrm{F}_{\mathrm{Fn}}$ is the major structural component of Tfp. All studies so far have failed to purify and structurally characterize these Tfp-like structures. Therefore, it is not possible to establish which pilin is the major subunit of Tfp in the different subspecies and strains studied. However, our results provide evidence that pilin-like proteins from Francisella are capable of interacting with components of an established Tfp system. Additionally, comparative studies of these particular systems have a unique potential to increase our understanding of the basic genotype-phenotype relationships underlying Tfp-related biology. For example, $F$. tularensis subspecies appear to lack a homologue of the 'canonical' PilM Tfp assembly factor present in virtually all other type IVa pilin Tfp-expressing species (Gil et al., 2004; Larsson et al., 2005). Moreover, the pilT genes (encoding the pilus retraction ATPase in Tfp systems) in subsp. holarctica strains were reported to carry identical nonsense mutations leading to a truncated protein which, based on all available data on this class of ATPases, would lead to disrupted function (Satyshur et al., 2007). Similarly, the pilE4 genes (orthologous to the gene encoding FTT0861) of subsp. holarctica strains carry identical frame-shift mutations leading to dramatic structural alterations in the C-terminal segment of the ORF. These latter findings are consistent with the idea that the functions served by the corresponding products are no longer associated with a fitness advantage to these strains and that the genes are undergoing decay. Thus, changes in Tfp-related genes and their products may be implicated in evolutionary events within Francisella species.

\section{ACKNOWLEDGEMENTS}

We are indebted to A. Pugsley (Pasteur Institute, Paris) and A. Filloux (IBSM-CNRS, Marseille Cedex) for the gift of plasmids and antibodies. This work was supported by funds from the Research Council of Norway Functional Genomics initiative (FUGE) directed through The Consortium of Advanced Microbial Sciences and Technologies (CAMST) (M.K. and H.C.W.-L.), the Swedish Research Council (A.F.) and the Kempe Foundation (E.S.). We thank Åshild Vik, Jennifer Ritchie, Moa Lavander and Jeanette Bröms for critical reading of the manuscript.

\section{REFERENCES}

Aas, F., Wolfgang, M., Frye, S., Dunham, S., Løvold, C. \& Koomey, M. (2002). Competence for natural transformation in Neisseria gonorrhoeae: components of DNA binding and uptake linked to type IV pilus expression. Mol Microbiol 46, 749-760.

Aas, F., Egge-Jacobsen, W., Winther-Larsen, H., Løvold, C., Hitchen, P., Dell, A. \& Koomey, M. (2006). Neisseria gonorrhoeae type IV pili undergo multisite, hierarchical modifications with phosphoethanolamine and phosphocholine requiring an enzyme structurally related to lipopolysaccharide phosphoethanolamine transferases. J Biol Chem 281, 2771227723.

Aas, F., Vik, A., Vedde, J., Koomey, M. \& Egge-Jacobsen, W. (2007a). Neisseria gonorrhoeae O-linked pilin glycosylation: functional analyses define both the biosynthetic pathway and glycan structure. Mol Microbiol 65, 607-624.

Aas, F., Winther-Larsen, H., Wolfgang, M., Frye, S., Løvold, C., Roos, N., van Putten, J. \& Koomey, M. (2007b). Substitutions in the N-terminal alpha helical spine of Neisseria gonorrhoeae pilin affect Type IV pilus assembly, dynamics and associated functions. Mol Microbiol 63, 69-85.

Alm, R. \& Mattick, J. (1996). Identification of two genes with prepilinlike leader sequences involved in type 4 fimbrial biogenesis in Pseudomonas aeruginosa. J Bacteriol 178, 3809-3817.

Alm, R., Bodero, A., Free, P. \& Mattick, J. (1996a). Identification of a novel gene, pilZ, essential for type 4 fimbrial biogenesis in Pseudomonas aeruginosa. J Bacteriol 178, 46-53.

Alm, R., Hallinan, J., Watson, A. \& Mattick, J. (1996b). Fimbrial biogenesis genes of Pseudomonas aeruginosa: pilW and pilX increase the similarity of type 4 fimbriae to the GSP protein-secretion systems and pilY1 encodes a gonococcal PilC homologue. Mol Microbiol 22, 161-173.

Bradley, D. \& Pitt, T. (1974). Pilus-dependence of four Pseudomonas aeruginosa bacteriophages with non-contractile tails. J Gen Virol 24, $1-15$. 
Carbonnelle, E., Helaine, S., Nassif, X. \& Pelicic, V. (2006). A systematic genetic analysis in Neisseria meningitidis defines the Pil proteins required for assembly, functionality, stabilization and export of type IV pili. Mol Microbiol 61, 1510-1522.

Chakraborty, S., Monfett, M., Maier, T., Benach, J., Frank, D. \& Thanassi, D. (2008). Type IV pili in Francisella tularensis: roles of pilF and pilT in fiber assembly, host cell adherence, and virulence. Infect Immun 76, 2852-2861.

d'Enfert, C. \& Pugsley, A. (1987). A gene fusion approach to the study of pullulanase export and secretion in Escherichia coli. Mol Microbiol 1, 159-168.

Dennis, D., Inglesby, T., Henderson, D., Bartlett, J. G., Ascher, M. S., Eitzen, E., Fine, A. D., Friedlander, A. M., Hauer, J. \& other authors (2001). Tularemia as a biological weapon: medical and public health management. JAMA 285, 2763-2773.

Durand, E., Bernadac, A., Ball, G., Lazdunski, A., Sturgis, J. \& Filloux, A. (2003). Type II protein secretion in Pseudomonas aeruginosa: the pseudopilus is a multifibrillar and adhesive structure. J Bacteriol 185, 2749-2758.

Elleman, T., Hoyne, P., Stewart, D., McKern, N. \& Peterson, J. (1986). Expression of pili from Bacteroides nodosus in Pseudomonas aeruginosa. J Bacteriol 168, 574-580.

Forsberg, A. \& Guina, T. (2007). Type II secretion and type IV pili of Francisella. Ann N Y Acad Sci 1105, 187-201.

Forslund, A., Kuoppa, K., Svensson, K., Salomonsson, E., Johansson, A., Byström, M., Oyston, P. C., Michell, S. L., Titball, R. W. \& other authors (2006). Direct repeat-mediated deletion of a type IV pilin gene results in major virulence attenuation of Francisella tularensis. Mol Microbiol 59, 1818-1830.

Freitag, N., Seifert, H. \& Koomey, M. (1995). Characterization of the pilF-pilD pilus-assembly locus of Neisseria gonorrhoeae. Mol Microbiol 16, 575-586.

Fullner, K. \& Mekalanos, J. (1999). Genetic characterization of a new type IV-A pilus gene cluster found in both classical and El Tor biotypes of Vibrio cholerae. Infect Immun 67, 1393-1404.

Gallagher, L., McKevitt, M., Ramage, E. \& Manoil, C. (2008). Genetic dissection of the Francisella novicida restriction barrier. J Bacteriol 190, 7830-7837.

Gil, H., Benach, J. \& Thanassi, D. (2004). Presence of pili on the surface of Francisella tularensis. Infect Immun 72, 3042-3047.

Golovliov, I., Sjöstedt, A., Mokrievich, A. \& Pavlov, V. (2003). A method for allelic replacement in Francisella tularensis. FEMS Microbiol Lett 222, 273-280.

Hager, A., Bolton, D., Pelletier, M., Brittnacher, M., Gallagher, L., Kaul, R., Skerrett, S., Miller, S. \& Guina, T. (2006). Type IV pili-mediated secretion modulates Francisella virulence. Mol Microbiol 62, 227-237.

Han, X., Kennan, R., Davies, J., Reddacliff, L., Dhungyel, O., Whittington, R., Turnbull, L., Whitchurch, C. \& Rood, J. (2008). Twitching motility is essential for virulence in Dichelobacter nodosus. J Bacteriol 190, 3323-3335.

Hegge, F., Hitchen, P., Aas, F., Kristiansen, H., Løvold, C., EggeJacobsen, W., Panico, M., Leong, W. Y., Bull, V. \& other authors (2004). Unique modifications with phosphocholine and phosphoethanolamine define alternate antigenic forms of Neisseria gonorrhoeae type IV pili. Proc Natl Acad Sci U S A 101, 10798-10803.

Helaine, S., Dyer, D., Nassif, X., Pelicic, V. \& Forest, K. (2007). 3D structure/function analysis of PilX reveals how minor pilins can modulate the virulence properties of type IV pili. Proc Natl Acad Sci U S A 104, 15888-15893.

Hollis, D., Weaver, R., Steigerwalt, A., Wenger, J., Moss, C. \& Brenner, D. (1989). Francisella philomiragia comb. nov. (formerly
Yersinia philomiragia) and Francisella tularensis biogroup novicida (formerly Francisella novicida) associated with human disease. J Clin Microbiol 27, 1601-1608.

Hoyne, P., Haas, R., Meyer, T., Davies, J. \& Elleman, T. (1992). Production of Neisseria gonorrhoeae pili (fimbriae) in Pseudomonas aeruginosa. J Bacteriol 174, 7321-7327.

Källström, H., Islam, M., Berggren, P. \& Jonsson, A. (1998). Cell signaling by the type IV pili of pathogenic Neisseria. J Biol Chem 273, 21777-21782.

Khan, A., Morse, S. \& Lillibridge, S. (2000). Public-health preparedness for biological terrorism in the USA. Lancet 356, 1179-1182.

Kirn, T., Bose, N. \& Taylor, R. (2003). Secretion of a soluble colonization factor by the TCP type 4 pilus biogenesis pathway in Vibrio cholerae. Mol Microbiol 49, 81-92.

Koomey, J. \& Falkow, S. (1987). Cloning of the recA gene of Neisseria gonorrhoeae and construction of gonococcal recA mutants. J Bacteriol 169, 790-795.

Laemmli, U. K. (1970). Cleavage of structural proteins during the assembly of the head of bacteriophage T4. Nature 227, 680-685.

Larsson, P., Oyston, P., Chain, P., Chu, M. C., Duffield, M., Fuxelius, H. H., Garcia, E., Hälltorp, G., Johansson, D. \& other authors (2005). The complete genome sequence of Francisella tularensis, the causative agent of tularemia. Nat Genet 37, 153-159.

Long, C., Hayes, S., van Putten, J., Harvey, H., Apicella, M. \& Seifert, H. (2001). Modulation of gonococcal piliation by regulatable transcription of pilE. J Bacteriol 183, 1600-1609.

Lu, H., Motley, S. \& Lory, S. (1997). Interactions of the components of the general secretion pathway: role of Pseudomonas aeruginosa type IV pilin subunits in complex formation and extracellular protein secretion. Mol Microbiol 25, 247-259.

Maier, B., Koomey, M. \& Sheetz, M. (2004). A force-dependent switch reverses type IV pilus retraction. Proc Natl Acad Sci U S A 101, 1096110966.

Martin, P., Watson, A., McCaul, T. \& Mattick, J. (1995). Characterization of a five-gene cluster required for the biogenesis of type 4 fimbriae in Pseudomonas aeruginosa. Mol Microbiol 16, 497-508.

Mattick, J. (2002). Type IV pili and twitching motility. Annu Rev Microbiol 56, 289-314.

Mattick, J., Whitchurch, C. \& Alm, R. (1996). The molecular genetics of type-4 fimbriae in Pseudomonas aeruginosa - a review. Gene 179, 147-155.

Merz, A., So, M. \& Sheetz, M. (2000). Pilus retraction powers bacterial twitching motility. Nature 407, 98-102.

Mörner, T. (1992). The ecology of tularaemia. Rev Sci Tech 11, 1123 1130.

Nudleman, E. \& Kaiser, D. (2004). Pulling together with type IV pili. J Mol Microbiol Biotechnol 7, 52-62.

Nudleman, E., Wall, D. \& Kaiser, D. (2006). Polar assembly of the type IV pilus secretin in Myxococcus xanthus. Mol Microbiol 60, 16-29.

O'Toole, G. \& Kolter, R. (1998). Flagellar and twitching motility are necessary for Pseudomonas aeruginosa biofilm development. Mol Microbiol 30, 295-304.

Park, H., Wolfgang, M. \& Koomey, M. (2002). Modification of type IV pilus-associated epithelial cell adherence and multicellular behavior by the PilU protein of Neisseria gonorrhoeae. Infect Immun 70, 38913903.

Patel, P., Marrs, C., Mattick, J., Ruehl, W., Taylor, R. \& Koomey, M. (1991). Shared antigenicity and immunogenicity of type 4 pilins expressed by Pseudomonas aeruginosa, Moraxella bovis, Neisseria gonorrhoeae, Dichelobacter nodosus, and Vibrio cholerae. Infect Immun 59, 4674-4676. 
Peabody, C., Chung, Y., Yen, M., Vidal-Ingigliardi, D., Pugsley, A. \& Saier, M. J. (2003). Type II protein secretion and its relationship to bacterial type IV pili and archaeal flagella. Microbiology 149, 30513072.

Petersen, J. \& Schriefer, M. (2005). Tularemia: emergence/reemergence. Vet Res 36, 455-467.

Rohmer, L., Fong, C., Abmayr, S., Wasnick, M., Larson Freeman, T. J., Radey, M., Guina, T., Svensson, K., Hayden, H. S. \& other authors (2007). Comparison of Francisella tularensis genomes reveals evolutionary events associated with the emergence of human pathogenic strains. Genome Biol 8, R102.

Sambrook, J., Fritsch, E. F. \& Maniatis, T. (1989). Molecular Cloning: a Laboratory Manual, 2nd edn. Cold Spring Harbor, NY: Cold Spring Harbor Laboratory.

Sandström, G., Tärnvik, A., Wolf-Watz, H. \& Löfgren, S. (1984). Antigen from Francisella tularensis: nonidentity between determinants participating in cell-mediated and humoral reactions. Infect Immun 45, 101-106.

Satyshur, K., Worzalla, G., Meyer, L., Heiniger, E., Aukema, K., Misic, A. \& Forest, K. (2007). Crystal structures of the pilus retraction motor PilT suggest large domain movements and subunit cooperation drive motility. Structure 15, 363-376.

Sauvonnet, N., Gounon, P. \& Pugsley, A. (2000). PpdD type IV pilin of Escherichia coli K-12 can be assembled into pili in Pseudomonas aeruginosa. J Bacteriol 182, 848-854.

Skerker, J. \& Berg, H. (2001). Direct observation of extension and retraction of type IV pili. Proc Natl Acad Sci U S A 98, 6901-6904.

Strom, M. \& Lory, S. (1993). Structure-function and biogenesis of the type IV pili. Annu Rev Microbiol 47, 565-596.

Strom, M., Nunn, D. \& Lory, S. (1993). A single bifunctional enzyme, PilD, catalyzes cleavage and N-methylation of proteins belonging to the type IV pilin family. Proc Natl Acad Sci U S A 90, 2404-2408.

Svensson, K., Larsson, P., Johansson, D., Byström, M., Forsman, M. \& Johansson, A. (2005). Evolution of subspecies of Francisella tularensis. J Bacteriol 187, 3903-3908.

Tärnvik, A. (1989). Nature of protective immunity to Francisella tularensis. Rev Infect Dis 11, 440-451.

Tärnvik, A. \& Berglund, L. (2003). Tularaemia. Eur Respir J 21, 361373.

Tønjum, T. \& Koomey, M. (1997). The pilus colonization factor of pathogenic neisserial species: organelle biogenesis and structure/ function relationships - a review. Gene 192, 155-163.

Tønjum, T., Freitag, N., Namork, E. \& Koomey, M. (1995). Identification and characterization of pilG, a highly conserved pilusassembly gene in pathogenic Neisseria. Mol Microbiol 16, 451-464.

Tyeryar, F. \& Lawton, W. (1970). Factors affecting transformation of Pasteurella novicida. J Bacteriol 104, 1312-1317.

Vignon, G., Köhler, R., Larquet, E., Giroux, S., Prévost, M., Roux, P. \& Pugsley, A. (2003). Type IV-like pili formed by the type II secreton: specificity, composition, bundling, polar localization and surface presentation of peptides. J Bacteriol 185, 3416-3428.

Vik, A., Aas, F., Anonsen, J., Bilsborough, S., Schneider, A., EggeJacobsen, W. \& Koomey, M. (2009). Broad spectrum O-linked protein glycosylation in the human pathogen Neisseria gonorrhoeae. Proc Natl Acad Sci U S A 106, 4447-4452.

Waldor, M. \& Mekalanos, J. (1996). Lysogenic conversion by a filamentous phage encoding cholera toxin. Science 272, 1910-1914.

Whipp, M., Davis, J., Lum, G., de Boer, J., Zhou, Y., Bearden, S., Petersen, J., Chu, M. \& Hogg, G. (2003). Characterization of a novicida-like subspecies of Francisella tularensis isolated in Australia. J Med Microbiol 52, 839-842.

Whitchurch, C., Hobbs, M., Livingston, S., Krishnapillai, V. \& Mattick, J. (1991). Characterisation of a Pseudomonas aeruginosa twitching motility gene and evidence for a specialised protein export system widespread in eubacteria. Gene 101, 33-44.

Winther-Larsen, H., Hegge, F., Wolfgang, M., Hayes, S., van Putten, J. \& Koomey, M. (2001). Neisseria gonorrhoeae PilV, a type IV pilusassociated protein essential to human epithelial cell adherence. Proc Natl Acad Sci U S A 98, 15276-15281.

Winther-Larsen, H., Wolfgang, M., Dunham, S., van Putten, J., Dorward, D., Løvold, C., Aas, F. \& Koomey, M. (2005). A conserved set of pilin-like molecules controls type IV pilus dynamics and organelleassociated functions in Neisseria gonorrhoeae. Mol Microbiol 56, 903917.

Winther-Larsen, H., Wolfgang, M., van Putten, J., Roos, N., Aas, F., Egge-Jacobsen, W., Maier, B. \& Koomey, M. (2007). Pseudomonas aeruginosa Type IV pilus expression in Neisseria gonorrhoeae: effects of pilin subunit composition on function and organelle dynamics. J Bacteriol 189, 6676-6685.

Wolfgang, M., Lauer, P., Park, H., Brossay, L., Hébert, J. \& Koomey, M. (1998a). PilT mutations lead to simultaneous defects in competence for natural transformation and twitching motility in piliated Neisseria gonorrhoeae. Mol Microbiol 29, 321-330.

Wolfgang, M., Park, H., Hayes, S., van Putten, J. \& Koomey, M. (1998b). Suppression of an absolute defect in type IV pilus biogenesis by loss-of-function mutations in pilT, a twitching motility gene in Neisseria gonorrhoeae. Proc Natl Acad Sci U S A 95, 14973-14978.

Wolfgang, M., van Putten, J., Hayes, S. \& Koomey, M. (1999). The comP locus of Neisseria gonorrhoeae encodes a type IV prepilin that is dispensable for pilus biogenesis but essential for natural transformation. Mol Microbiol 31, 1345-1357.

Wolfgang, M., van Putten, J., Hayes, S., Dorward, D. \& Koomey, M. (2000). Components and dynamics of fiber formation define a ubiquitous biogenesis pathway for bacterial pili. EMBO J 19, 64086418.

Zogaj, X., Chakraborty, S., Liu, J., Thanassi, D. \& Klose, K. (2008). Characterization of the Francisella tularensis subsp. novicida type IV pilus. Microbiology 154, 2139-2150.

Edited by: L. S. Frost 